cerns are, to a large extent, acknowledged and highlighted at various points throughout the book. Whether they are satisfactorily dealt with will most likely remain a point of contention.

Ultimately, such questions underscore (rather than detract from) the importance and relevance of Power and Meaning Making in an EAP Classroom. In addition to problematizing the implementation of critical literacy in this specific EAP classroom, Chun provides a rich overview of the literature underpinning a critical approach to English language teaching. Readers interested in delving deeper into this literature will find all the direction they need in the extensive references cited by Chun; those less inclined to delve into background literature will nonetheless find the wealth of practical classroom materials to be of value. This combination of a perspicacious theoretical overview and an insightful investigation of crucial context-specific pedagogical issues makes Chun's book essential reading for the EAP practitioner.

Jeff Brown

\title{
The Reviewer
}

Dr. Jeff Brown is a professor in the Centre for Preparatory and Liberal Studies at George Brown College in Toronto, Ontario. His research interests focus on critical pedagogy and the ethics of English language teaching. His work has appeared in a variety of journals, including TESL Canada Journal, Dialogue, Language Problems and Language Planning, and Symposium.

\section{Computer Games and Language Learning}

\section{Mark Peterson}

New York, NY: Palgrave MacMillan, 2013, 167 pages, ISBN 978-1-137-00516-8

The power and potential of digital technologies are increasingly being harnessed and investigated for the purpose of supporting language learning. Mark Peterson's book, Computer Games and Language Learning, provides a concise, in-depth review of relevant literature and a case study for the purpose of answering two central questions: (a) Is the participation in computer gaming beneficial for language learners? and (b) Does computer gaming represent a paradigm shift in language education? To address each of the questions framing the book, Chapters 1 through 6 build a rationale for using computer games with language learners, leading to Chapter 7, wherein Peterson presents a case study of a massively multiplayer online role-playing game (MMORPG), and Chapter 8, in which he provides a conclusion and ideas for future directions.

Chapter 1 provides an introduction to the history of digital technologies in language education, beginning with mainframe computers introduced in the 1950s through to the inauguration and evolution of the field of computer-assisted language learning (CALL). The reader is also introduced to the potential of modern technologies, such as mobile communication devices 
to impact language learning in ways previously inconceivable in the 20th century. In Chapter 2, Peterson discusses fundamental definitions, theories, elements, and issues relating to computer games. Following this, in Chapter 3 he identifies elements of computer gaming that contribute to learning, specifically drawing from games studies, digital media perspectives, and literacy perspectives. The aim of Chapter 4 is to build a connection between second language acquisition theories, attending to both cognitive and social approaches, and the affordances provided by computer games for language learning. Chapters 5 and 6 present early and recent CALL research, respectively. Literature investigating computer gaming for language learning is reviewed in depth for the purpose of identifying common research findings and limitations, in turn informing Peterson's case study. The study, presented in Chapter 7, investigates a MMORPG used in an English as a foreign language context.

MMORPGs engage players in real-time online interactions with the goal of accomplishing a set of increasingly more challenging quests through cooperation with others. Peterson notes that sociocultural theory provides strong insights about language learning opportunities via the social interaction and collaborative role-play activity found within MMORPGs. Findings from the case study suggest that intermediate to advanced language learners experience high motivation and interest through the active production of the target language within online games and in cooperation with more capable gamers. This is commensurate with findings of similar studies. Further, through engagement within the MMORPG, learners engage in authentic, purposeful communication and are exposed to new vocabulary, resulting in lexical development and enhanced proficiency. However, learners with low language proficiency found the game register challenging, leading to feelings of frustration and limited interactions with more competent players. Technical issues, such as mandatory software updates, at times also hampered play within the MMORPG. Instructional training ahead of learners' own computer gaming was identified as instrumental to the success that all learners experienced within the MMORPG, regardless of language proficiency level. Despite the shortcomings associated with computer gaming, and in particular with MMORPGs, Peterson argues that computer gaming is beneficial for language learners.

While Peterson provides a strong case for the potential benefits of computer gaming for language education, he also concedes that gaming has not yet become mainstream in language training or in contemporary research. However, as technology advancements are made and increasingly userfriendly tools are incorporated into the design of computer games, there is potential for computer gaming to become increasingly viable in the language classroom. Peterson's book offers a comprehensive literature review and balanced approach that considers both the affordances and constraints of incorporating computer games into the language classroom. The book provides 
a straightforward read for teachers and academics wishing to learn more about the potential of integrating technologies, including MMORPGs, into language learning contexts.

\section{Wendy Chambers}

\section{The Reviewer}

Dr. Wendy Chambers is an adjunct professor in the TESL program at the University of Alberta. Her current research interests include computer-assisted language learning and online communicative presence.

\section{Books Available for Review, Vol. 33, Issue 1, 2015}

Farrell, T. S. C. (2016). From trainee to teacher: Reflective practice for novice teachers. Sheffield, England: Equinox.

Myles, J. (2015). Beyond methodology: English language learners K-12. Charlotte, NC: Information Age Publishing. 